\title{
Erratum to: Theoretical Study of the Electronic Excited States and Fluorescence Spectra of Squaraine in Solution
}

\author{
Hitoshi Ozawa · Kazunori Yashiro • Takuma Yamamoto • \\ Satoshi Yabushita
}

Published online: 17 October 2014

(C) Springer Science+Business Media New York 2014

\section{Erratum to: J Solution Chem DOI 10.1007/s10953-014-0224-x}

The original version of this article unfortunately contained a typo in Table 2. In the column headings of Table $2, \Delta \mathrm{G}(\mathrm{p}-\mathrm{p})$ should be changed to $\Delta \mathrm{G}(\mathrm{t}-\mathrm{t})$, also the table caption is modified. The corrected table is given below as:

Table $2 \mathrm{~S}_{0} / \mathrm{S}_{1}$ energy gaps $\{\Delta G(\mathrm{t}-\mathrm{t})\}$ and the heats of reaction $\{\Delta G(\mathrm{p}-\mathrm{t})\}$ from the common planar $\left(\mathrm{B}_{1 \mathrm{u}}\right)$ state to each of the twisted structures in $\mathrm{CH}_{2} \mathrm{Cl}_{2}$ and $\mathrm{MeOH}$ solvents (and in vacuum); the dihedral angles $\omega_{1}-\omega_{4}$ are defined with respect to the central four-membered ring in unit of degrees

\begin{tabular}{lrrrrll}
\hline Number & $\omega_{1}$ & $\omega_{2}$ & $\omega_{3}$ & $\omega_{4}$ & $\Delta G(\mathrm{t}-\mathrm{t})\left(\mathrm{eV}^{\mathrm{a}}\right)$ & $\Delta G(\mathrm{p}-\mathrm{t})\left(\mathrm{eV}^{\mathrm{a}}\right)$ \\
\hline 1 & 0 & 90 & 0 & 90 & $2.09,2.12(1.85)$ & $1.57,1.68(0.744)$ \\
2 & 90 & 90 & 90 & 90 & $1.24,1.25(1.09)$ & $0.857,0.921(0.371)$ \\
3 & 90 & 0 & 90 & 0 & $1.44,1.46(1.21)$ & $2.09,2.18(1.39)$ \\
4 & 0 & 90 & 0 & 0 & $2.26,2.23(2.03)$ & $0.946,0.975(0.246)$ \\
5 & 90 & 90 & 0 & 0 & $2.11,2.15(1.72)$ & $0.709,0.798(0.0559)$ \\
6 & 90 & 0 & 0 & 0 & $2.26,2.31(1.82)$ & $1.33,1.44(0.567)$ \\
\hline
\end{tabular}

a $1 \mathrm{eV}=96.5 \mathrm{~kJ} \cdot \mathrm{mol}^{-1}$

The online version of the original article can be found under doi:10.1007/s10953-014-0224-x.

H. Ozawa $\cdot$ K. Yashiro $\cdot$ T. Yamamoto $\cdot$ S. Yabushita $(\bowtie)$

Department of Chemistry, Faculty of Science and Technology, Keio University, 3-14-1 Hiyoshi,

Kohoku-ku, Yokohama 223-8522, Japan

e-mail: yabusita@chem.keio.ac.jp 